\title{
HPLC-DAD, ESI-MS/MS, and NMR of Lycopene Isolated From P. guajava L. and Its Biotechnological Applications
}

\author{
Adriany G. N. Amorim, Jessica M. T. Souza, Raimunda C. Santos, Beatriz Gullón, \\ Ana Oliveira, Luiz F. A. Santos, Adamor L. E. Virgino, Ana C. Mafud, \\ Helena M. Petrilli, Yvonne P. Mascarenhas, Cristina Delerue-Matos, \\ Manuela E. Pintado, and José R. S. A. Leite*
}

Abstract

Psidium guajava L. have been reported to be a rich source of antioxidant compounds. Its carotenoids have been highlighted by their high antioxidant capacity, which offers several benefits for human health. In this sense, lycopene isomers need to be identified. In this work, the comprehensive chemical characterization, by HPLCDAD, MS/MS, and NMR, of lycopene isolated from P. guajava L., antioxidant and antimicrobial activity of lycopene extracts and isolated lycopene are evaluated. The FTIR results reported a structure with $Z$ configuration, confirmed by UV-Vis, with $\lambda \max =448,473$, and $505 \mathrm{~nm}$ for $5-Z$ lycopene. Furthermore, MS/MS positive ionization shows one fragment $\mathrm{m} / \mathrm{z} 309$ [M-227] $^{+}$, relatively abundant for isolated lycopene. Experimental and Theoretical NMR studies revealed that guava may contain 5-Z lycopene because of the similarity found among the peaks. Lycopene extracts presented higher antioxidant activity than isolated lycopene, from both $P$. guajava L. and tomato, when measured by ABTS and ORAC $\left(r^{2}=0.9995\right.$ and $r^{2}=0.9992$, respectively). In addition, lycopene extract shows antibacterial efficacy against E. coli, S. aureus, and L. innocua, presenting $M B C$ values of $20 \mathrm{mg} \mathrm{mL}^{-1}$. These results suggest that lycopene extract have potential applicability for food, cosmetics, and pharmaceutical industry.

Practical Applications: Lycopene from P. guajava L. is characterized by HPLCDAD, MS, NMR, FTIR, and X-Ray, presented antioxidant capacity by ORAC and antibacterial efficacy against food pathogens.

\section{Introduction}

Psidium guajava L. is a species that grows in tropical and subtropical regions. The fruit, guava, has originally come from Mexico and Central America, but it is also very common in Brazil. Guava contains a high level of antioxidant compounds, such as vitamin $\mathrm{C}$ and carotenoids, especially lycopene. ${ }^{[1]}$

Lycopene is a natural carotenoid, ${ }^{[2]}$ which shows powerful antioxidant properties, even higher than $\beta$-carotene. It is usually found in red fruits as tomato and guava. ${ }^{[3]}$ This bioactive compound has attracted considerable attention in the last two decades due to its protective effects against several chronic diseases, particularly skin cancer, ${ }^{[4,5]}$ prostate cancer, lung cancer, ${ }^{[6]}$ cardiovascular diseases, ${ }^{[5]}$ and degenerative diseases. ${ }^{[1]}$

Many studies have focused on the use of tomato as the main source of lycopene in the development of functional products. ${ }^{[7]}$ Although lycopene extracts from tomato are the most studied and used according to the literature, it is worth pointing out that

\section{Keywords}

bioactivity, ESI-MS/MS, HPLC-DAD, lycopene, NMR

\footnotetext{
A. G. N. Amorim, J. M. T. Souza, R. C. Santos

Centre for Biodiversity Research and Biotechnology

Federal University of Piauí

São Sebastião Avenue, 2819, Reis Veloso, 64202-020,

Parnaíba, Piauí, Brazil

B. Gullón

Department of Chemical Engineering

Institute of Technology

University of Santiago de Compostela

15782, Santiago de Compostela, Spain

A. Oliveira, M. E. Pintado

Centre for Biotechnology and Fine Chemistry

Portuguese Catholic University

Arquiteto Lobão Vital Apartado Street, 2511, Asprela, Porto, Portugal

L. F. A. Santos

Bruker of Brasil Ltda

BBP Condominium

Barão de Mauá

Rod D. Pedro I, Km 87.5 (Northern runway), 12954-260, Atibaia,

São Paulo, Brazil
}

\author{
A. L. E. Virgino, H. M. Petrilli \\ Physical Institute \\ University of São Paulo \\ Matão street, bystreet R, 187 Block C, room 102, University City, \\ 05508090, São Paulo-SP, Brazil \\ A. C. Mafud, Y. P. Mascarenhas \\ São Carlos Physical Institute \\ University of São Paulo \\ 13566-590, São Carlos, São Paulo, Brazil \\ C. Delerue-Matos \\ REQUIMTE \\ Superior Engineering Institute of Porto \\ Polytechnic Institute of Porto \\ Porto, Portugal \\ Prof. J. R. S. A. Leite \\ Morphology Area \\ Faculty of Medicine \\ University of Brasília (UnB) \\ University campus Darcy Ribeiro, Asa Norte, 70910-900, \\ Brasília-DF, Brazil \\ E-mail: jrsaleite@gmail.com; jrleite@pq.cnpq.br
}


lycopene extract from guava is also of great biotechnological interest, once that lycopene and other carotenoids with antioxidant potential, such as $\beta$-carotene, are present in this fruit. ${ }^{[6]}$ Hence, once lycopene demand is growing, there is an increasing interest in exploiting alternative sources for its obtainment and studies on guava as an alternative source of lycopene and antioxidants could be a good option. ${ }^{[1]}$

Therefore, the development of new and rapid methodologies for the extraction, separation, and purification of lycopene in vegetables has been studied because lycopene is more efficient in preventing oxidative damage than $\beta$-carotene. ${ }^{[2]}$ However, these studies showed that there is a synergistic antioxidant activity of lycopene in combination with $\beta$-carotene and other carotenoids, such as lutein and $\beta$-cryptoxanthin, and this activity was more efficient in protecting liposome from oxidation than the individual carotenoid. ${ }^{[6]}$

Also in recent years, multiple drug resistance has been developed by some microorganisms due to the indiscriminate use of commercial antimicrobial drugs, commonly used for the treatment of infectious diseases. ${ }^{[8]}$ This situation has forced many researchers to find new substances from good sources, such as vegetables, which contain a number of bioactive compounds that can be used as alternative natural antimicrobials and antioxidants. ${ }^{[8,9]}$ Among these compounds, those related with antioxidant activity are subject of many research studies, due to their enormous importance in human health. ${ }^{[10]}$

To the best of our knowledge, the antimicrobial activity of lycopene from guava has not been reported in literature. The main objectives of this study were to perform the chemical characterization of lycopene extracts and isolated lycopene from guava by UV-Vis, Liquid chromatography, Mass Spectrometry, Nuclear Molecular Resonance; and to evaluate its antioxidant activity with two different methods (ABTS and ORAC), as well as its antibacterial activity against some of the most frequent food pathogens. These assessments would be helpful in the analysis of the carotenoid once not all of the lycopene isomers have been currently identified.

\section{Experimental Section}

\subsection{Sample Collection}

Samples were collected in the Coastal Tablelands, District of Piauí (DITALPI - EBV 4), $2^{\circ} 55^{\prime} \mathrm{S}$ latitude and $41^{\circ} 50^{\prime} \mathrm{W}$ longitude, located in Parnaíba - PI, during periods of higher productivity of guava, between the months of $08 / 2012$ to 08/2014. Reproductive branches were collected containing buds, flowers, and fruit to establish the voucher specimen. Species identification was performed using the Classification System ${ }^{[11]}$ and its nomenclature was confirmed in International Plant Names Index. ${ }^{[12]}$ The samples received the number 0286 at Delta of Parnaíba Herbarium - HDELTA-UFPI and were identified as P. guajava L. in its collection.

\subsection{Reagents}

Dichloromethane, Chloroform, Ethanol, and Amonium acetate were used for lycopene extraction, separation, and determination (analytical grade). Acetonitrile, Hexane, and Methanol were used for HPLC (chromatographic grade). Fluorescein, 2,2'-azo-bis-(2methylpropionamidine)-dihydrochloride (AAPH), 6-hydroxy-2, 5, 7, 8-tetramethylbroman-2-carboxylic acid (Trolox), and tomato lycopene standard were purchased from Sigma-Aldrich.

Guava from $P$. guajava L. $(\sim 0.09 \%$ of lycopene and $28.10 \pm 8.98$ moisture content) and Tomato from cultivate Anairis ( $\sim 0.05 \%$ of lycopene and $34.32 \pm 1.79$ moisture content) were used as samples in this work.

\subsection{Extraction of Lycopene}

Lycopene obtained from guava at high ripeness was used as antioxidant source. It was isolated from $100 \mathrm{~g}$ of guava in accordance with Amorim et al. ${ }^{[13]}$ patent. Details of the extraction conditions as temperature, time, and organic solvent volume are described more clearly in this patent. Guavas were washed with ethanol. Lycopene was extracted with dichloromethane. Subsequently, lycopene was isolated from the extract with the use of chloroform and ethanol, stored in solvent overnight under refrigeration at $4{ }^{\circ} \mathrm{C}$ and, after that, washed (ethanol) and dried using controlled low temperature. After the extraction and purification, the extract and isolated lycopene were stored at $-80^{\circ} \mathrm{C}$. The same extraction process was carried out with tomato (cultivate Anairis).

\subsection{High Performance Liquid Chromatography - HPLC-DAD}

The profile of guava and tomato extracts were conducted with Waters 2690 HPLC system with a 996 photodiode array (Waters Series 600, Massachusetts, USA), using a RPAQUEOUS Develosil $\mathrm{C}_{30}(4.6 \times 150 \mathrm{~mm}, 5 \mu \mathrm{m})$ column with a guard column containing the same stationary phase (Symmetry ${ }^{\mathbb{B}} \mathrm{C}_{18}$ ) and maintained at $25^{\circ} \mathrm{C}$. The mobile phase used was acetonitrile:methanol:hexane: dichloromethane:ammonium acetate (55:22:11.5:11.5:0.02 v/v/v/ $\mathrm{v} / \mathrm{w})$, under isocratic conditions, at $1.0 \mathrm{~mL} \mathrm{~min}^{-1}$. UV-Vis spectra were collected from 600 to $200 \mathrm{~nm}$ in steps of $2 \mathrm{~nm}$. The calibration curve (Figure S1, Supporting Information) was constructed with lycopene and was calculated as lycopene equivalent at $A_{472} \mathrm{~nm}$ as $\mathrm{mg} 100 \mathrm{~g}^{-1}$ of fresh biomass. ${ }^{[14]}$

\subsection{ESI - Mass Spectroscopy}

Lycopene mass spectra from guava were performed according to Pennathur et al. ${ }^{[15]}$ method, with modifications, using a Bruker maXis Impact mass spectrometer with electrospray source in positive ion mode. The samples were prepared by adding $50 \mu \mathrm{L}$ of Chloroform plus $450 \mu \mathrm{L}$ of Acetonitrile. A total of $50 \mu \mathrm{L}$ of this solution was diluted to $500 \mu \mathrm{L}$ in acetonitrile/water (75:25) and used for direct infusion. The ionization conditions were optimized as follows: The temperature of the dry gas source was maintained at $180^{\circ} \mathrm{C}$, the nebulizer pressure at 0.4 bars and dry gas at $4 \mathrm{~L} \mathrm{~min}^{-1}$. A capillary potential of $4.0 \mathrm{KV}$ and an end plate offset of $0.5 \mathrm{~V}$ were applied. Mass spectra were obtained in "full scan" mode from $m / z$ 50-3000. MS/MS experiments gave the characteristic fragmentation of the precursor ions, using 
different collision energies (5-18 eV) and nitrogen as collision gas. OTOFControl and DataAnalysis were used for acquisition and data processing. Before MS and MS/MS experiments, the instrument was calibrated with tune mix solution covering the measured mass range (Agilent P/N G1969-85000).

\subsection{FTIR}

The identification of lycopene isolated from guava fruit was investigated by FTIR using a Shimadzu IRAffinity-1 spectrometer in the spectral range 4000 to $400 \mathrm{~cm}^{-1}$ resolution with $\mathrm{KBr}$ window.

\subsection{X-Ray (XRD)}

X-ray diffractogram (XRD) data were obtained at the Laboratory of X-ray Crystallography of IFSC/USP using a Rigaku Rotaflex diffractometer equipped with graphite monochromator and rotating anode tube, operating with $\mathrm{Cu} \mathrm{Ka}, 50 \mathrm{kV}$, and $100 \mathrm{~mA}$. Powder diffraction patterns were obtained in step scanning mode, $2 \theta=5-50^{\circ}$, step of $0.02^{\circ}$ and $5 \mathrm{~s} / \mathrm{step}$. The crystallinity percentage was obtained by the ratio between the sums of the peak areas to the area of the amorphous broad hallo due to the amorphous phase.

\subsection{NMR}

To proton NMR experiments, guava extracts were dissolved in deuterated chloroform $\left(\mathrm{CDCl}_{3}\right)$ according to Takehara et al. ${ }^{[16]}$ ${ }^{1} \mathrm{H}$ spectrum was collected on a $400 \mathrm{MHz}$ NMR instrument BRUKER, model AVANCE III 14.1 and 9.4 Tesla. Tetramethylsilane was used to reference the spectrum. Topspin 1.3 software (Bruker) was used to transform and integrate the NMR spectrum.

\subsection{Computational Details}

The electronic structure of all lycopene isomers was investigated in the framework of the Density Functional Theory ${ }^{[17]}$ in the Kohn-Sham scheme (1995) as implemented in the Gaussian $09^{[18]}$ software package. The initial structures were designed by Discovery Studio 3.5 $5^{[19]}$ and optimized using the B3LYP ${ }^{[20]}$ functional and 6-311G (d, p) basis set. The theoretical NMR chemical shifts were calculated with the same basis, functional and the Gauge Invariance Atomic Orbital (GIAO) method ${ }^{[21]}$ using tetramethylsilane (TMS) as the reference molecule.

\subsection{In Vitro Antioxidant Activity}

\subsubsection{ABTS}

Antioxidant activity was assessed using ABTS radical cation discoloration assay. ${ }^{[22]}$ Pure lycopene and dried extracts from guava and tomato were dissolved in ethanol. ABTS $^{+}$stock solution was prepared through the reaction of $7 \mathrm{mM}$ ABTS and $2.45 \mathrm{mM}$ of potassium persulphate, the oxidant agent. The working solution of $\mathrm{ABTS}^{+}$was obtained by diluting the stock solution in ethanol to obtain absorption of $0.700 \pm 0.02$ at $734 \mathrm{~nm}$ (Shimadzu 1240 UV-Visible spectrophotometer). A volume of $50 \mu \mathrm{L}$ was taken from the sample extract and added to $950 \mu \mathrm{L}$ of $\mathrm{ABTS}^{+\cdot}$ solution and absorbance readings were made exactly 6 min after initial mixing. The calibration curve was made with Trolox in the range of $40-400 \mu \mathrm{M}$. The results were expressed as Trolox equivalents in $\mu \mathrm{mol}$ Troloxg ${ }^{-1}$. The following calibration curve (equation 1) was used:

$y=-0.0015 x+0.6639\left(r^{2}=0.9995\right)$

\subsubsection{ORAC}

The Oxygen radical absorbance capacity (ORAC-FL) assay was based on that proposed by Ref.[23] with modifications. Briefly, the reaction was carried out at $40^{\circ} \mathrm{C}$ in $75 \mathrm{mM}$ phosphate buffer $(\mathrm{pH} 7.4)$ and the final assay mixture $(200 \mu \mathrm{L})$ contained fluorescein $(70 \mathrm{nM}), \mathrm{AAPH}(14 \mathrm{mM})$, and antioxidant (Trolox [10 at $80 \mu \mathrm{M}$ ] or sample [at different concentrations]). The fluorescence was recorded during $137 \mathrm{~min}$ (104 cycles). A FLUOstar OPTIMA plate reader (BMG Labtech, Offenburg, Germany), with $485 \mathrm{~nm}$ excitation and $520 \mathrm{~nm}$ emission filters, was used. The equipment was controlled by the FLUOstar Control software version (1.32 R2) for fluorescence measurement. Black polystyrene 96-well microplates (Nunc, Denmark) were used. AAPH and Trolox solutions were prepared daily and fluorescein was diluted from a stock solution $(1.17 \mathrm{mM})$ in $75 \mathrm{mM}$ phosphate buffer ( $\mathrm{pH}$ 7.4). All reaction mixtures were prepared in duplicate and at least three independent runs were performed for each sample. ORAC-FL values were expressed as $\mu \mathrm{mol}$ Trolox $\mathrm{g}^{-1}$. The following calibration curve was used:

$y=0.4638 x+4.7490\left(r^{2}=0.9992\right)$

where: $x=$ ORAC value in $\mu \mathrm{mol}$ Troloxg ${ }^{-1} ; y=$ area below fluorescence decay curve (AUC = integral of the area under the curve) of sample or standard minus the area below fluorescence decay curve of blank (Figure 5). AUC can be calculated through equation $3^{[23]}$ :

$\mathrm{AUC}=\left(\frac{R_{1}}{R_{1}}\right)+\left(\frac{R_{2}}{R_{1}}\right)+\left(\frac{R_{3}}{R_{1}}\right)+\ldots+\left(\frac{R_{\mathrm{n}}}{R_{1}}\right)$

where $R_{1}$ is the fluorescence read at the onset of the reaction and $R_{\mathrm{n}}$ is the last measurement.

Net AUC $=$ AUCsample - AUCblank

\subsection{Statistical Analysis}

All the assays were carried out in triplicate. The results are expressed as means values and standard deviation (SD) by 
ANOVA. Statistical significance was evaluated by Students- $t$ test at $5 \%$ level of significance $(p<0.05)$.

\subsection{Antibacterial Activity}

\subsubsection{Microorganisms and Culture Conditions}

The antibacterial activities of lycopene obtained from tomato and guava were tested against the following bacterial strains: Listeria innocua (NCTC 10528) Staphylococcus aureus (isolated from food sample, accession number $18 \mathrm{~N}$, collection from CINATE), Escherichia coli and Bacillus cereus (DSM 4313). Strains were stored in cryovials with glycerol at $15 \%(\mathrm{v} / \mathrm{v})$ and maintained at $-80^{\circ} \mathrm{C}$ until use. Active cultures for experiments were grown in sterile Mueller-Hinton broth (MHB) (Biokar Diagnostics, Beauvais, France) at $37^{\circ} \mathrm{C}$ for $6-8 \mathrm{~h}$, and then an aliquot from each culture was transferred to fresh MHB and cultured overnight at $37^{\circ} \mathrm{C}$. Purity and cell numbers were checked by plate observation, counting colonies were enumerated and total viable cells $\left(\mathrm{CFU} \mathrm{g}^{-1}\right.$ ) were determined.

\subsubsection{Determination of $M I C$ and $M B C$}

Lycopene antimicrobial activity was tested using a microdilution assay in accordance to the Clinical and Laboratory Standards Institute guidelines described in the document M07-A9. Dried extract of lycopene was dissolved in dimethyl sulfoxide (DMSO) to reach a final concentration of $60 \mathrm{mg} \mathrm{mL}^{-1}$. Briefly, MIC was assayed in the microplate reader (FLUOstar, OPTIMA, BGM Labtech), using sterile 96 wells trays. Each well was filled with a total volume of $300 \mu \mathrm{L}$ containing ca. $10^{6}$ colony forming units $\left(\mathrm{CFU} \mathrm{mL} \mathrm{m}^{-1}\right)$ of tested bacteria, fresh MHB, and diluted extract of lycopene. Tested extract concentrations were ranged from 10 to $60 \mathrm{mg} \mathrm{mL}^{-1}$. Negative controls contained non-inoculated medium with extract samples and positive control wells were prepared with inoculated medium without extract samples.

Bacterial growth was monitored during $24 \mathrm{~h}$ at $37^{\circ} \mathrm{C}$ through absorbance measurements at $620 \mathrm{~nm}$ each hour. MIC was determined by observing the lowest concentration of extract which inhibited bacterial growth (indicated by clear wells). To determine the MBC values, solutions with an extract concentration equal or higher to the MIC values were used, assuming a maximum concentration of $30 \mathrm{mg} \mathrm{mL}^{-1}$. Briefly, $50 \mu \mathrm{L}$ were taken from each well of MIC assays (no significant variations in absorbance were observed), and spread on a plate containing agar medium. After incubation at $37^{\circ} \mathrm{C}$ for $24 \mathrm{~h}$, the lowest extract concentration that showed a reduction of $99.9 \%$ of initial $\mathrm{CFU} \mathrm{mL} \mathrm{L}^{-1}$ was considered the MBC value.

\section{Results}

\subsection{Chemical Characterization}

UV-Vis spectra of lycopene extract from guava, lycopene standard, and isolated lycopene from guava in ethanol were analyzed (Figure 2). The comparison between the standard and the samples shows the presence of lycopene in the extract and in the isolated lycopene, from guava and tomato, by the detection of the same maximum wavelengths $-\lambda \max$ (Ethanol) - 448, 473, $505 \mathrm{~nm}$.

Differences in chemical composition for lycopene extracts from guava (LEG) and tomato (LET) were observed by HPLCDAD analyses and are shown in Figure 1. The retention times (Rt) of the samples were compared with those found for lycopene standard (Table 1). The chromatographic profile shows the presence of lycopene and other carotenoids between 600 and $200 \mathrm{~nm}$ (Figure 2). Based on the absorption spectra of the reference analytical standards, the samples presented the same $\mathrm{Rt}=10.5 \mathrm{~min}$ and $\lambda \max =473 \mathrm{~nm}$, besides 448 and $505 \mathrm{~nm}$ for 5 $Z$ lycopene (Figure 2). Also based on the Rt of the diode array spectra, the signals on 9.7 and 16.1 min were attributed to other carotenoids (Table 1), considering the fact that UV-Vis spectra showed their characteristic $\lambda \max =442,467$, and $499 \mathrm{~nm}$ to $13-Z$ lycopene and $\lambda \max =451$ and $478 \mathrm{~nm}$ to $\beta$-carotene in both samples (Figure 2).

According to the chromatograms, LEG, LET, LPG, and LPT showed a peak of lycopene on Rt of $10.5 \mathrm{~min}$ at $473 \mathrm{~nm}$ when compared to the Rt of 9.1 min observed for the lycopene standard (Figure 1). After the purification, both samples showed similar lycopene isomers (Figure 1D and E), which may be related to a $Z$ isomer of lycopene (Table 1). Using the linear regression attributed to the Peak area vs concentration (Figure S1, Supporting Information), it was possible to observe that lycopene was the most abundant carotenoid in LET sample, while $\beta$-carotene was the highest in LEG (Table S1, Supporting Information). After the purification process, both extracts provided a high purity lycopene (Figure 1).

Figure 3 shows the experimental and theoretical MS spectra of tomato lycopene standard (3A) and lycopene from guava (3B). Positive radical ion species were observed, with $\mathrm{m} / z 536.4381$ and 536.4363, for tomato standard and guava lycopene, respectively. This data showed that the standard and lycopene extracted from guava presented similar mass spectra in mass spectrometry analysis, which is in accordance with the data for theoretical lycopene molecular formula. The MS/MS experiments at $m / z 536.43$ from guava showed two main fragments for

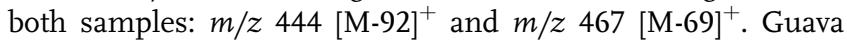
lycopene MS/MS $(18 \mathrm{eV})$ is shown in Figure $3 \mathrm{C}$ and an ion fragment at $m / z 309.2787$ [M-227] $^{+}$indicates the presence of lycopene isomers in guava. Based on the chemical structure of lycopene, this fragment can be related to lycopene with $Z$ configuration (Table 1). The MS/MS (18 eV) spectrum of tomato lycopene standard is shown in Figure 3D, however, its fragmentation did not show the peak mentioned in MS/MS data from guava.

A vibrational wavelength of IR spectrum is shown in Figure S2, Supporting Information. The lycopene present in the extract showed a very strong swing vibration peak of $E$ R$\mathrm{HC}=\mathrm{CH}-\mathrm{R}$ at $960 \mathrm{~cm}^{-1}$, a very strong stretching peak of nonsymmetric methyl $(\mathrm{CH} \mathrm{sp})$ at $2916 \mathrm{~cm}^{-1}$, as strong as a symmetric methylene $\left(\mathrm{CH} \mathrm{sp}^{2}\right)$ at $2848 \mathrm{~cm}^{-1}$; a medium peak of methyl deformation $(\mathrm{CH} \mathrm{sp})$ at $1365 \mathrm{~cm}^{-1}$ and a medium bending peak of methylene $(\mathrm{CH} \mathrm{sp})$ at $1446 \mathrm{~cm}^{-1}$; a medium stretching peak of $(\mathrm{CH}-\mathrm{CH})$ at $1082 \mathrm{~cm}^{-1}$; a weak peak of stretching vibration of $Z$ vinylene $\left(\mathrm{R}-\mathrm{CH}=\mathrm{CH}-\mathrm{R}^{\prime}\right)$ at 

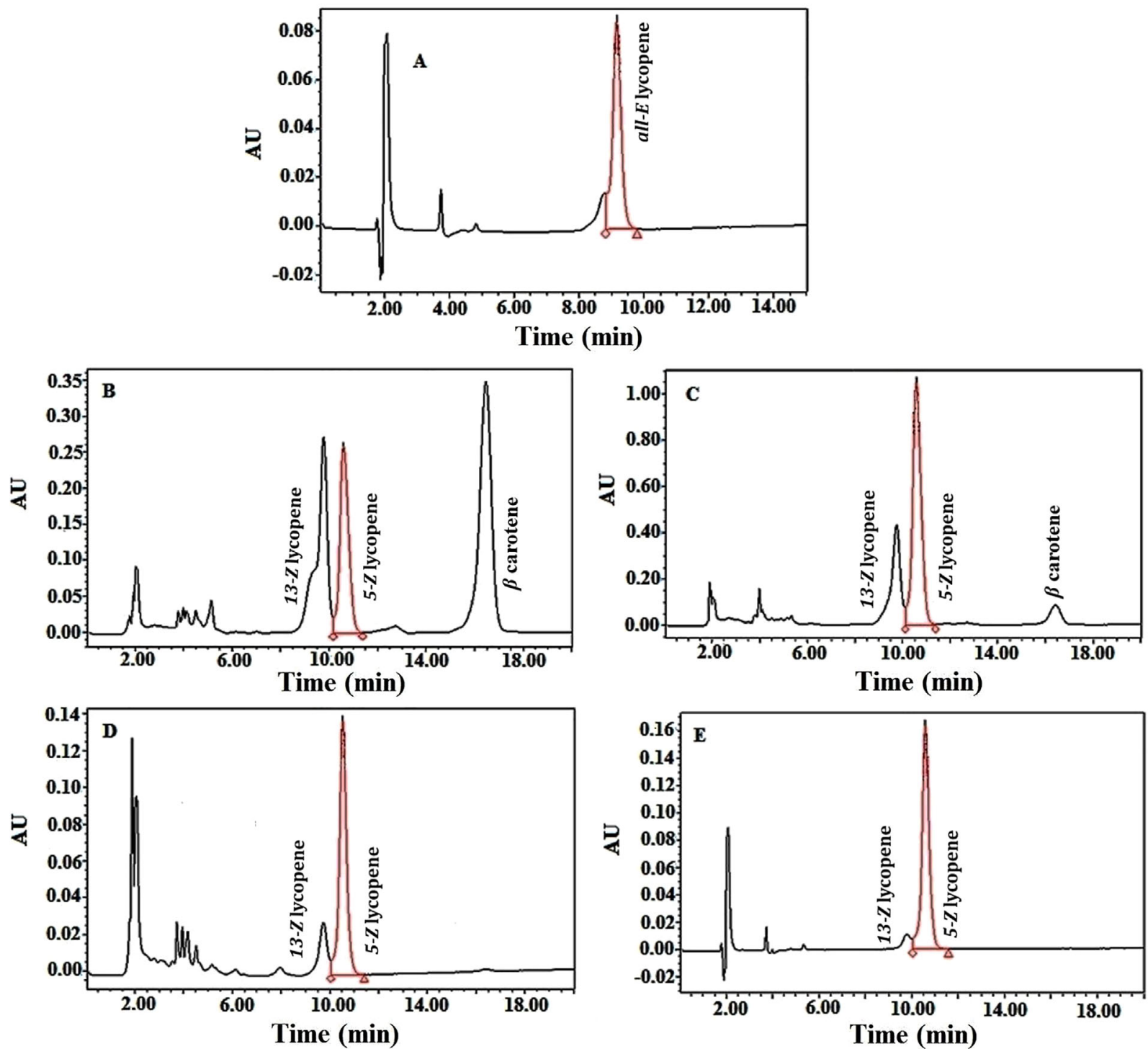

Figure 1. Chromatograms by HPLC-DAD: (A) Lycopene standard, (B) LEG, (C) LET, (D) LPG, and (E) LPT.

$1625 \mathrm{~cm}^{-1}$ and other at $3037 \mathrm{~m}^{-1}$ corresponding to the stretching vibration peak of $=\mathrm{C}-\mathrm{H}$. There was a weak absorption peak between 730 and $665 \mathrm{~cm}^{-1}$, which was the absorption band of $\mathrm{Z} \mathrm{R}-\mathrm{HC}=\mathrm{CH}-\mathrm{R}$.

$\mathrm{XRD}$, with main $h k l$ reflections identified, presents defined peaks at $2 \theta=5.46,12.42,21.66,24.06,24.80,27.04$, and $29.76^{\circ}$, and a broad peak centered at $2 \theta=12.42^{\circ}$, indicating a degree of crystallinity (Figure 4 ). The degree of crystallinity of the samples was determined from XRD patterns and it was determined that the sample has $74.91 \%$ of crystallinity. Despite the presence of an amorphous halo, linked to the non-recrystallization of the sample, it is possible to observe characteristic peaks of the standard, $\beta$-carotene (JCPDS card, $\left.\mathrm{N}^{\circ} 14-0912\right)$, space group $\mathrm{P}$ $21 / \mathrm{n}$, with $a=7.656(2) \AA, \quad b=9.445(5) \AA, \quad c=23.536(15) \AA$, $\beta=93.41(2)^{\circ}$, and 2 units per unit cell.

Experiments using NMR as a characterization technique were performed to complement guava lycopene identification evidences.
The experimental and theoretical NMR spectra are shown in Figure S3, Supporting Information. The aim here was to unravel which lycopene isomer was present in the guava extract. For this purpose, theoretical ${ }^{1} \mathrm{H}$ and ${ }^{13} \mathrm{C}$ chemical shift calculations were performed for all-E, 13-Z, 9-Z, and 5-Zlycopene isomers, which are also presented in Figure S3A and S3B, Supporting Information. Tentative assignments, using $1 \mathrm{ppm}$ as criteria of match between theoretical and experimental results are shown in Table 2 and 3. Notice that, for easy reference, the experimental values were repeated in each column, each time that a correspondence with a given theoretical value was found.

\subsection{In Vitro Antioxidant Activity}

Antioxidant activity was determined by two different assays, which measured samples potential of reducing free radicals 
Table 1. HPLC-DAD and ESI-MS/MS characteristics of carotenoids from P. guajava L. (LEG and LPG), tomato (cultivate Anairis, LET, and LPT), and lycopene standard.

\begin{tabular}{|c|c|c|c|}
\hline \multirow{2}{*}{$\frac{\text { Sample }}{{ }^{\text {acCarotenoid }}}$} & \multirow{2}{*}{$\begin{array}{c}\text { Lycopene standard } \\
\text { all-E lycopene }\end{array}$} & \multicolumn{2}{|c|}{ LPG } \\
\hline & & 5-Z lycopene & 13-Z lycopene \\
\hline${ }^{\mathrm{a}} \lambda \max (\mathrm{nm})$ & $448,473,505$ & $448,473,505$ & $442,467,499$ \\
\hline${ }^{b}$ Rt (min) & 9.16 & 10.59 & 9.76 \\
\hline \multirow[t]{3}{*}{${ }^{c} \mathrm{MS}$} & {$[\mathrm{M}]^{+} 536.4363$} & {$[\mathrm{M}]^{+} 536.4381$} & - \\
\hline & {$[\mathrm{M}+1]^{+} 537.4401$} & {$[\mathrm{M}+1]^{+} 537.4420$} & \\
\hline & {$[\mathrm{M}+2]^{+} 538.4440$} & {$[\mathrm{M}+2]^{+} 538.4458$} & \\
\hline \multirow[t]{6}{*}{${ }^{c} M S / M S$} & {$[\mathrm{M}]^{+} 536$} & {$[\mathrm{M}]^{+} 536$} & - \\
\hline & {$[\mathrm{M}-69]^{+} 467$} & {$[\mathrm{M}-69]^{+} 467$} & \\
\hline & {$[\mathrm{M}-92]^{+} 444$} & {$[\mathrm{M}-92]^{+} 444$} & \\
\hline & {$[\mathrm{M}-161]^{+} 375$} & {$[\mathrm{M}-161]^{+} 375$} & \\
\hline & [M-267] 269 & {$[\mathrm{M}-227]^{+} 309$} & \\
\hline & & {$[M-267]^{+} 269$} & \\
\hline Sample & LEG & & \\
\hline${ }^{\mathrm{a} C}$ Carotenoid & 5-Z lycopene & 13-Z lycopene & $\beta$-carotene \\
\hline${ }^{\mathrm{a}} \lambda \max (\mathrm{nm})$ & $448,473,505$ & $442,467,499$ & 451,478 \\
\hline${ }^{\mathrm{b}} \mathrm{Rt}$ (min) & 10.59 & 9.78 & 16.16 \\
\hline Sample & LET & & \\
\hline${ }^{\mathrm{a}}$ Carotenoid & $5-Z$ lycopene & 13-Z lycopene & $\beta$-carotene \\
\hline${ }^{\mathrm{a}} \lambda \max (\mathrm{nm})$ & $448,473,505$ & $442,467,499$ & 451,478 \\
\hline${ }^{\mathrm{b}} \mathrm{Rt}(\mathrm{min})$ & 10.57 & 9.75 & 17.13 \\
\hline Sample & LPT & & \\
\hline${ }^{\mathrm{a} C}$ Carotenoid & 5-Z lycopene & 13-Z lycopene & \\
\hline${ }^{\mathrm{a}} \lambda \max (\mathrm{nm})$ & $448,473,505$ & $442,467,499$ & \\
\hline${ }^{\mathrm{b}} \mathrm{Rt}$ (min) & 10.58 & 9.79 & \\
\hline
\end{tabular}

a Tentative identification based on DAD-UV-Vis detector (Figure 2).

${ }^{\mathrm{b}}$ HPLC-DAD retention times (Figure 1).

${ }^{\mathrm{c}}$ Mass spectra relative (Figure 3).

scavenging activity. The TEAC values of individual compounds were determined according to the decreases in the absorbance (inhibition) of the ABTS+". solution, as a function of the amount of antioxidant. All samples had antioxidant activity and assays showed high linear regression coefficients: LEG $\left(r^{2}=0.9736\right)$, LPG $\left(r^{2}=0.9940\right)$, LET $\left(r^{2}=0.9934\right)$, and LPT $\left(r^{2}=0.9861\right)$. The mean TEAC values $\left(r^{2}=0.9995\right)$ for guava and tomato extract were $2890 \pm 34$ and $1963 \pm 50 \mu \mathrm{M}$ Trolox g $^{-1}$, respectively. The analysis of variance revealed that, as observed for LEG and LET levels, there were significant differences $(p<0.05)$ in the TEAC values between guava and tomato extracts. The same assays showed no significant differences between LPG and LPT (Table S3, Supporting Information).

The resultant antioxidant capacity obtained by ORAC (Figure 5) also provided an excellent determination coefficient value, showing that LEG in the same line was significantly different $(p<0.05)$ between the samples. It is possible to observe that significant and good linear regression coefficients by ORAC were found to the extracts and pure lycopene for both samples from guava and from tomato LEG $\left(r^{2}=0.9982\right)$, LPG $\left(r^{2}=0.9765\right)$, LET $\left(r^{2}=0.9605\right)$, and LPT $\left(r^{2}=0.9575\right)$, all correlations were significant at $p<0.05$ (Table S3, Supporting Information). Simple linear regression was carried out to assess correlations of ORAC values and the levels of antioxidants. The values for tomato (LET $297.92 \pm 36.37$ and LPT $283.28 \pm 55.76 \mu \mathrm{Mol}$ Troloxg ${ }^{-1}$ ) were significantly lower than those for guava extract (LEG $402.80 \pm 44.40 \mu \mathrm{Mol}$ Trolox g ${ }^{-1}$ ).

\subsection{In Vitro Antibacterial Activity}

The antimicrobial activities of carotenoid extracts rich in lycopene, expressed as minimum inhibitory concentrations (MIC) and minimum bactericidal concentration (MBC), were evaluated against three Gram positive (S. aureus, B. cereus, and $L$. innocua) and one Gram negative (E. coli) bacterial strains (Table S2, Supporting Information). The analysis of the results obtained showed that both extracts were capable of inhibiting the growth of all the microorganisms studied (Table S2, Supporting Information).

Both extracts presented MIC values of $15 \mathrm{mg} \mathrm{mL}^{-1}$ for all studied bacteria, except $B$. cereus, which presented a MIC of $30 \mathrm{mg} \mathrm{mL}^{-1}$, what is expected since it is a spore-forming bacterium. MBC values for E. coli, S. aureus, and L. innocua were $20 \mathrm{mg} \mathrm{mL}^{-1}$. It was not possible to determine the $\mathrm{MBC}$ value for B. cereus, probably because the $\mathrm{MBC}$ value for this spore-forming bacterium could be higher than the tested concentrations $\left(60 \mathrm{mg} \mathrm{mL}^{-1}\right)$.

\section{Discussion}

\subsection{Chemical Characterization}

Analysis and spectral confirmation of carotenoids were based on characteristic UV-Vis spectra, a fundamental condition for the identification and evaluation of carotenoids chemistry, as lycopene, in food. ${ }^{[16,24]}$ These data were compared to lycopene standard, used as a reference, once the characteristic UV-Vis spectrum of lycopene standard is well reported in literature. It shows three maximum wavelengths, 444,471 , and $502 \mathrm{~nm},{ }^{[3]}$ due to the hyperconjugated double bonds in the molecule (Figure S4, Supporting Information), which contains 11 conjugated double bonds and two unconjugated double bonds. ${ }^{[5,15]}$

Differences between the maximum wavelengths by UV-vis were observed by Arathi et al. ${ }^{[2]}$ and Honda et al. ${ }^{[4]}$ In addition, Honda et al. ${ }^{[4]}$ showed that all-E lycopene and $5-Z$ lycopene had the same $\lambda \max$ values when dissolved in the same solvent, while the other lycopene isomers had different $\lambda \max$ values. Silva et al. ${ }^{[25]}$ reported $\lambda=425,451$, and $478 \mathrm{~nm}$ as maximum absorbance values for $\beta$-carotene. Similar results were found in this study for both 5 - $Z$ lycopene and $\beta$-carotene (Table 1 ).

Thus, liquid chromatography, with a $\mathrm{C}_{30}$ column, was used to separate lycopene isomers in a carotenoid mixture from guava, as this is the most common technique applied for the separation of isomers from vegetal source. ${ }^{[14,24]}$ Data comparison between the samples and lycopene standard chromatograms is shown in Figure 1, identifying the peaks with different retention times for 

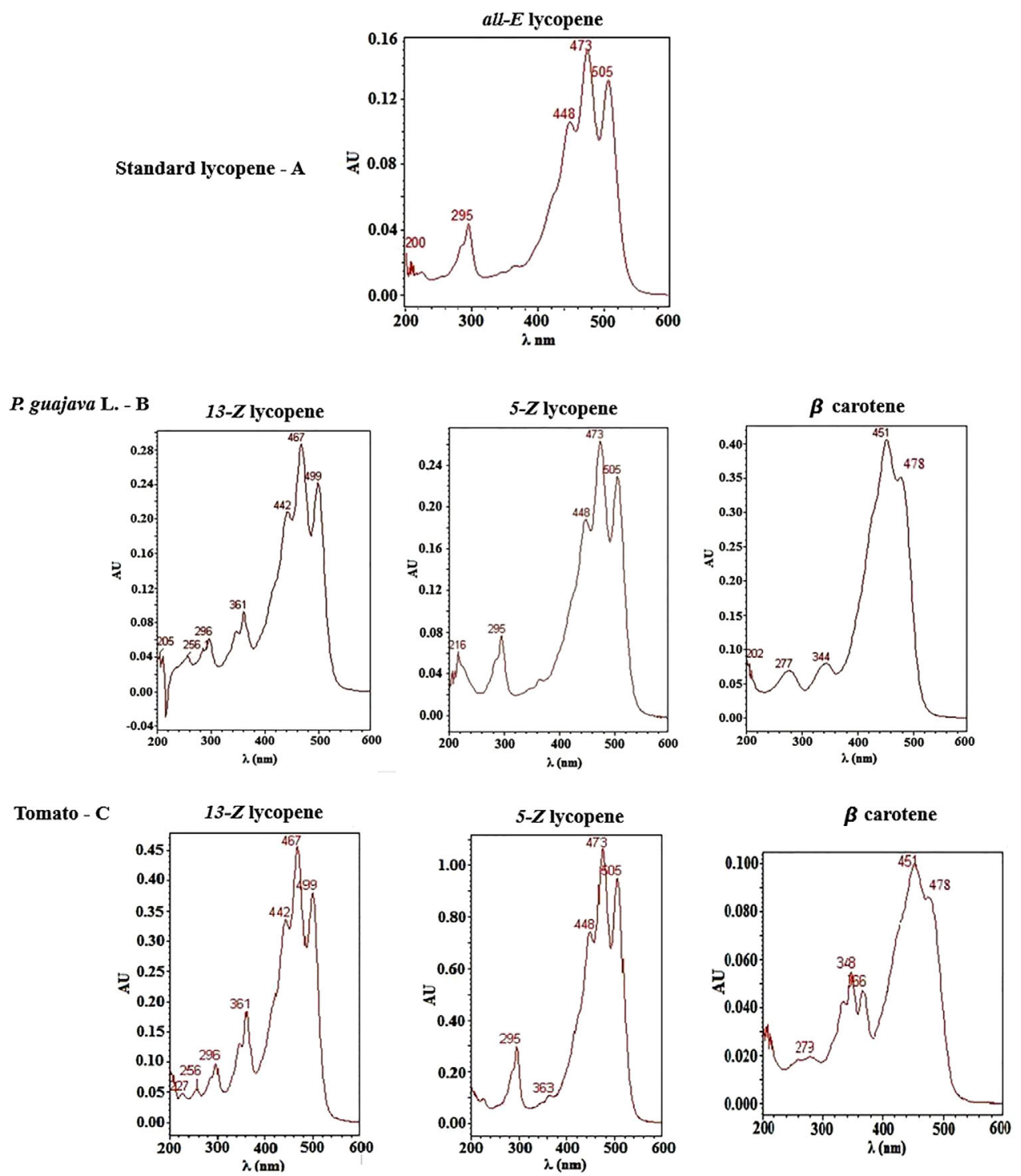

Isolated lycopene from $P$. guajava L. - D

Isolated lycopene from tomato - $\mathrm{E}$
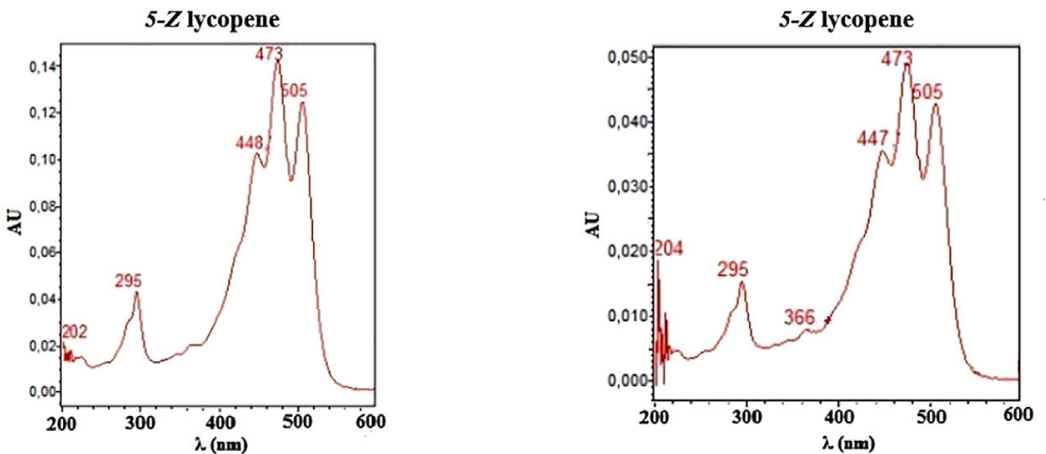

Figure 2. UV-vis spectra (HPLC-DAD) of Lycopene standard (A), LEG (B), LET (C), LPG (D), LPT (E).

each lycopene isomer, that were confirmed for its retention times and also by the characteristic UV-Vis spectra (Figure 2) obtained by a diode array detector. Similar data were shown by Arathi et al. $^{[24]}$ on their analysis of lycopene isomers.
The fragments yielded after positive ionization of lycopene $(m / z 536.43)$ and the ones detected at $m / z 444$ and 467 correspond, respectively, to the loss of the isoprene unit, as well as toluene, and are molecular ions obtained from lycopene 


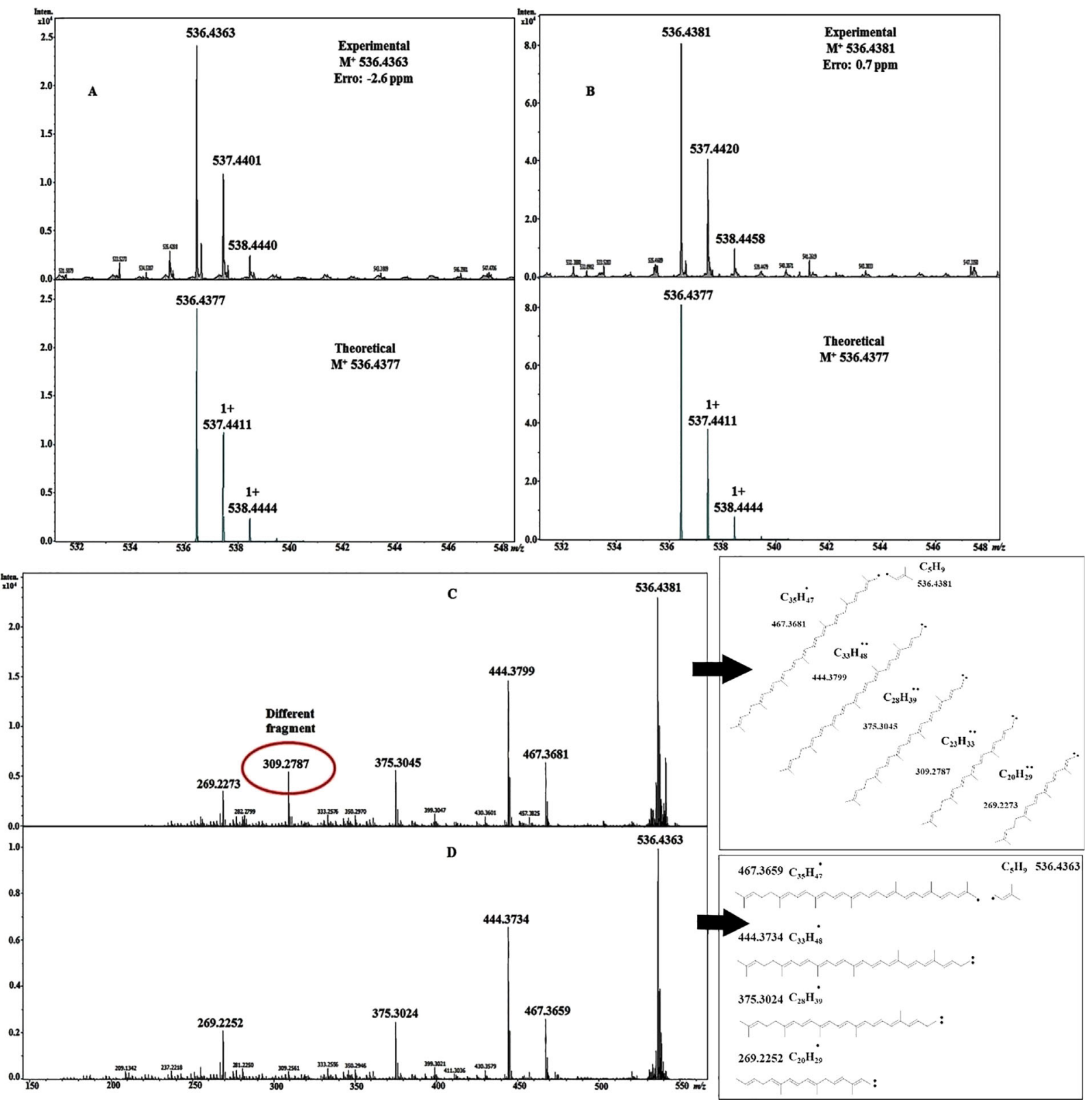

Figure 3. Mass spectra of lycopene standard (A), LPG (B), MS/MS of $m / z 536.4381$ (C), and $m / z 536.4363$ (D).

isomers. ${ }^{[6]}$ In addition, it was observed that $Z$ and all-E lycopene isomers may be distinguished by the relative abundances of ions fragments at $m / z 269,444,467$, and 536 , when produced by mass spectra of $\mathrm{APCI}^{+}$(Atmospheric Pressure Chemical Ionization Positive Ionization) product ions and their relative abundance at 18-eV collision-induced dissociation, as shown in Figure 3. On the other hand, a relative abundance of the ions $m / z 305$ for 13Zlycopene and $m / z 301$ to all-E lycopene was also observed, using positive ionization and the same collision energy. ${ }^{[24]}$ This may explain the ion at $m / z 309$ for $5-Z$ lycopene in LEG, which presented a relative abundance for guava lycopene.

IR results also indicated that there were $Z$ isomers in the sample due to a weak absorption peak between 730 and $665 \mathrm{~cm}^{-1}$ corresponding to the absorption band of $\mathrm{Z} \mathrm{R}-\mathrm{HC}=\mathrm{CH}-\mathrm{R}^{\left[{ }^{[26]}\right.}$ There was also the presence of a symmetric methylene $\left(\mathrm{CH} \mathrm{sp}{ }^{2}\right)$, a medium peak of methyl deformation $\left(\mathrm{CH} \mathrm{sp}{ }^{3}\right)$ and a medium bending peak of methylene $\left(\mathrm{CH} \mathrm{sp}{ }^{2}\right)$, as well as a medium stretching peak of $(\mathrm{CH}-\mathrm{CH})$, a weak peak of $Z$ vinylene stretching vibration $\left(\mathrm{R}-\mathrm{CH}=\mathrm{CH}-\mathrm{R}^{\prime}\right)^{[27]}$ and other stretching vibration peak of $=\mathrm{C}-\mathrm{H}$. On the other hand, a very strong swing vibration peak of $E \mathrm{R}-\mathrm{HC}=\mathrm{CH}-\mathrm{R}$ and a very strong stretching peak of non-symmetric methyl $\left(\mathrm{CH} \mathrm{sp}^{3}\right)$ were also observed Qiu et al. ${ }^{[28]}$ Bunghez et al. ${ }^{[29]}$ found typical weak bands of lipids (1730$1766 \mathrm{~cm}^{-1}$ and $3000-2800 \mathrm{~cm}^{-1}$ ) in tomato samples. Similar data were obtained in guava lycopene sample $\left(1716-1732 \mathrm{~cm}^{-1}\right.$ and $2848-3037 \mathrm{~cm}^{-1}$ ). 


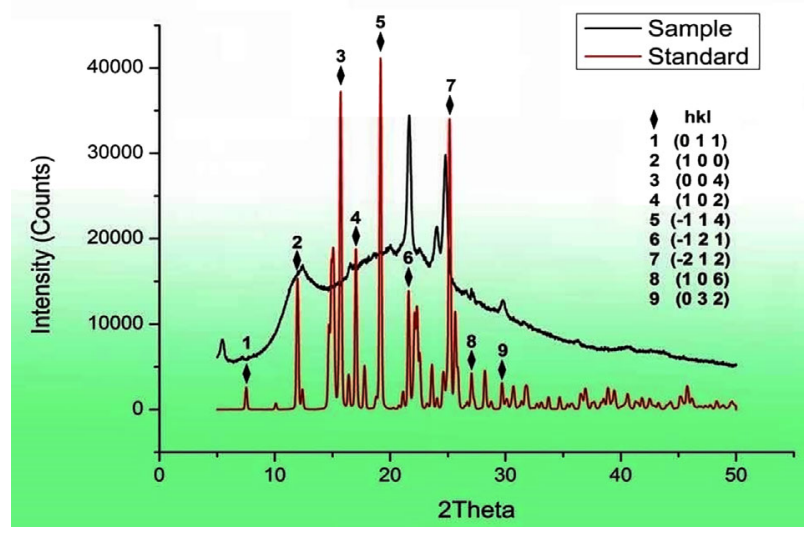

Figure 4. X-ray diffractogram of isolated lycopene from $P$. guajava $\mathrm{L}$.

First, by visual inspection of Figure S3, Supporting Information, it is possible to see that the larger discrepancies occur between the experimental and the $9-Z$ isomer (the whole spectrum was shifted in this case), indicating that this form might not be present in the sample. In Table 2 and 3 it is possible to verify that the $5-Z$ isomer, with $C-18$ (45\% of all carbons present in the molecule) was the isomer that had more combinations of ${ }^{13} \mathrm{C}$ chemical shift values with the theoretical results, followed by the $13-Z$, with 12 (35\%), the all-E with 10 (25\%) and, finally, 9-Z with only 2 (5\%). Although the $13-Z$ isomer cannot be completely discarded from the analysis, the results indicated that $5-Z$ was mostly present in the experimental sample.

Only geometric structures of a few lycopene $Z$ isomers have been thoroughly identified from natural sources. ${ }^{[30]}$ The structure of isolated lycopene was ascertained by ${ }^{1} \mathrm{H}$ and ${ }^{13} \mathrm{C}$ NMR spectroscopic analyses, and the ${ }^{13} \mathrm{C}$ assignments are listed along with those of lycopene isomers (Tables 2 and 3). The shift differences $(\Delta \delta)$ were larger around the all-E lycopene in $\mathrm{CDCl}_{3}$ and the main assignments were showed at $5-Z$ and $13-Z$ lycopene. The values of this last isomer were in agreement with the data previously reported in $\mathrm{CDCl}_{3} \cdot{ }^{[5]}$

Lycopene characterization was completed by X-ray. Lebail et al. ${ }^{[31]}$ fit was proceeded and the cell parameters obtained for the compound were $a=7.77953 \AA$, $b=9.43577 \AA, c=23.36130$ $\AA$, and $\beta=92.91781^{\circ}$. Peak positions shifts should be assigned to the structural difference between the $\beta$-carotene and lycopene. Results point to the need for sample recrystallization in order to increase the percentage of crystallinity and data accuracy, however, it is possible to state the crystalline character of lycopene. Probably, physical properties as crystallinity of all-Elycopene were changing it for the $Z$-isomers proprieties due to temperature used, which significantly decreases the all-E content and, consequently, increases the $Z$-isomers content. ${ }^{[32]}$

Storage conditions and thermal treatments affect the stability of lycopene in commercially available gazpachos due to the fact that lycopene can undergo $E / Z$ isomerization and this process increases the proportion of $5-Z$ lycopene $(2.72 \%)$ and decreases $13-Z$ lycopene $(7.27 \%)$ in these products. ${ }^{[3]}$

Thermal processing and solvents used, severely affects the isomerization of all-E lycopene during the steps of extraction process. ${ }^{[2,4,16]}$ Strong solvent effect generated 5-Zlycopene as the predominant isomer when $\mathrm{CH}_{2} \mathrm{Cl}_{2}$ or $\mathrm{CH}_{2} \mathrm{Br}_{2}$ was used, independently of the heating temperature. On the other hand, $13-Z$ isomer was preferentially formed by the use of other solvents such as $\mathrm{CHCl}_{3} \cdot{ }^{[4,15]}$

Besides, interestingly, in function of temperature applied in the process, the $5-Z$ isomer should be the one formed in greater concentration, for being more thermodynamically stable than the other lycopene isomers, ${ }^{[34]}$ for this reason, $9-Z$ production was declined. Comparison data of theoretical and experimental NMR (Table S1 and S2, Supporting Information) demonstred for LPG, by this process, low similarity whit $9-Z$ and more similarity to $5-Z$. DAD-UV-vis data (Figure 2 and eTable S1, Supporting Information) also proved similarity to $5-Z$ for LPG and LPT.

Several studies have reported that all-E and 5-Z lycopene have similar physicochemical properties such as free energy and activation energy, as well as their solubilities, because, a major moisture of $5-Z$ was acquired after process isomerization described in this study. ${ }^{[34]}$

\subsection{In Vitro Antioxidant Activity}

The $E / Z$ geometric isomerization at arbitrary sites within the 11 conjugated double bonds, offer varying characteristics related to lycopene antioxidant capacity and bioavailability. ${ }^{[30]}$ Studies showed that $\mathrm{C}_{40}$ carotenes have the ability to scavenge ABTS+", and among them, lycopene is considered the most efficient. Its high antioxidant activity ${ }^{[2]}$ suggests that these carotenes may also exhibit scavenging capacity toward ABTS $+\cdot{ }^{[35]}$ The higher the number of conjugated double bonds, the stronger the activity of the carotenoid. This increased ability of carotenes to scavenge ABTS $^{+}$grows with the extension of the chromophore and a maximum overlap of the carbon-carbon double bond molecular orbitals. ${ }^{[36]}$

These data are in agreement with the observed by Stinco et al., ${ }^{[35]}$ who reported high positive correlation between lycopene and the TEAC values for different commercial samples of tomato extracts, which were slightly higher than those previously reported in literature.

Dávila-Aviña et al. ${ }^{[37]}$ also found significant and high regression coefficients to ORAC $\left(350.85 \mu \mathrm{mol} \mathrm{TE}{ }^{-1}\right)$. These values were similar to those found for lycopene from tomato in this study (Table 3). These reports have shown that ORAC assay can be used as a tool for evaluating lycopene antioxidant activity and to understand better the relationship between lycopene concentration and antioxidant activity in different food systems. $^{[35,38]}$

In addition, Eller et al. ${ }^{[38]}$ suggested that the antioxidant capacity of tomato seed oil is mainly due to the presence of two lycopene isomers $(Z$ and $E$ ) even in the presence of $\beta$-carotene, because lycopene is a stronger antioxidant than other carotenoids. This fact seemed to suggest that these carotenes may also exhibit reducing power of free radicals scavenging activity by ABTS and ORAC.

According to the literature, carotenoid extracts from fruits showed higher antioxidant activity. ${ }^{[14]}$ As shown by El-Raey et al. ${ }^{[6]}$ lycopene, $\beta$-carotene, and other carotenoids might be more suitable in combinational use rather than in single use, 
Table 2. Assignments of the experimental data considering the calculated results.

\begin{tabular}{|c|c|c|c|c|c|c|}
\hline \multicolumn{7}{|l|}{${ }^{13} \mathrm{C}$} \\
\hline Label & $\begin{array}{l}\text { Theoretical } \\
13-Z \text { (ppm) }\end{array}$ & $\begin{array}{l}\text { Experimental } \\
\quad(\mathrm{ppm})\end{array}$ & & Label & $\begin{array}{l}\text { Theoretical } \\
9-Z \text { (ppm) }\end{array}$ & $\begin{array}{c}\text { Experimental } \\
(\mathrm{ppm})\end{array}$ \\
\hline C-1 & 25.89 & 25.85 & & C-1 1 & 38.65 & \\
\hline C-2 & 141.92 & & & $C-2$ & 162.08 & \\
\hline$C-3$ & 132.59 & 132.80 & & C-3 & 147.27 & \\
\hline C-4 & 38.79 & 40.39 & & C-4 & 46.52 & \\
\hline C-5 & 45.52 & & & $C-5$ & 55.79 & \\
\hline C-6 & 149.30 & & & C-6 & 169.17 & \\
\hline C-7 & 124.27 & 124.96 & 124.11 & C-7 & 153.10 & \\
\hline C- 8 & 131.65 & 131.89 & 131.71 & C-8 & 150.58 & \\
\hline C-9 & 136.59 & 136.70 & 136.32 & C-9 & 150.08 & \\
\hline C. 10 & 146.23 & & & C- 10 & 161.77 & \\
\hline C-11 & 133.88 & & & $C-11$ & 153.53 & \\
\hline C-12 & 129.17 & & & C- 12 & 147.00 & \\
\hline C-13 & 133.54 & & & C-13 & 159.72 & \\
\hline C- 14 & 141.85 & & & C- 14 & 162.98 & \\
\hline C-15 & 134.91 & & & C- 15 & 155.45 & \\
\hline C-16 & 132.29 & & & $C-16$ & 153.03 & \\
\hline C-17 & 22.65 & 22.84 & & C- 17 & 39.31 & \\
\hline C-18 & 23.80 & & & C- 18 & 35.97 & \\
\hline C-19 & 16.48 & & & $C-19$ & 42.43 & \\
\hline$C-20$ & 20.59 & & & C- 20 & 33.03 & \\
\hline$C-1^{\prime}$ & 25.48 & & & $C-1^{\prime}$ & 44.36 & \\
\hline$C-2^{\prime}$ & 144.88 & & & $\mathrm{C}-2^{\prime}$ & 163.30 & \\
\hline$C-3^{\prime}$ & 129.73 & & & $C-3^{\prime}$ & 145.86 & \\
\hline$C-4^{\prime}$ & 31.93 & 32.08 & & $C-4^{\prime}$ & 48.99 & \\
\hline C-5' & 38.12 & & & $C-5^{\prime}$ & 54.08 & \\
\hline$C-6^{\prime}$ & 151.46 & & & $C-6^{\prime}$ & 169.33 & \\
\hline C- $7^{\prime}$ & 132.43 & & & $C-7^{\prime}$ & 151.18 & \\
\hline$C-8^{\prime}$ & 131.42 & & & $C-8^{\prime}$ & 150.81 & \\
\hline C- $-9^{\prime}$ & 135.06 & 135.56 & & C- $-9^{\prime}$ & 156.70 & \\
\hline C- $10^{\prime}$ & 149.74 & & & $C-10^{\prime}$ & 164.79 & \\
\hline C- $-11^{\prime}$ & 130.37 & 130.23 & & $C-11^{\prime}$ & 152.77 & \\
\hline C- $12^{\prime}$ & 130.10 & & & $C-12^{\prime}$ & 150.36 & \\
\hline C- $13^{\prime}$ & 137.51 & 137.51 & & $C-13^{\prime}$ & 159.92 & \\
\hline C- $14^{\prime}$ & 144.44 & & & $C-14^{\prime}$ & 161.70 & \\
\hline C- $15^{\prime}$ & 134.25 & & & C- $15^{\prime}$ & 154.40 & \\
\hline C- $16^{\prime}$ & 130.09 & & & $C-16^{\prime}$ & 152.42 & \\
\hline C- $17^{\prime}$ & 25.08 & & & $C-17^{\prime}$ & 40.96 & 40.39 \\
\hline C- $18^{\prime}$ & 20.10 & & & C- $18^{\prime}$ & 35.55 & \\
\hline C-19' & 19.53 & & & C-19' & 32.94 & 32.08 \\
\hline C- $-20^{\prime}$ & 15.35 & & & $C-20^{\prime}$ & 31.78 & \\
\hline
\end{tabular}

Labeling according to Figure S3A (Supplementary Information).
Table 3. Assignments of the experimental data considering the calculated results.

\begin{tabular}{|c|c|c|c|c|c|}
\hline \multicolumn{6}{|l|}{${ }^{13} \mathrm{C}$} \\
\hline Label & $\begin{array}{c}\text { Theoretical } 5-Z \\
(\mathrm{ppm})\end{array}$ & $\begin{array}{l}\text { Experimental } \\
\quad(\mathrm{ppm})\end{array}$ & Label & $\begin{array}{l}\text { Theoretical all-E } \\
\text { (ppm) }\end{array}$ & $\begin{array}{c}\text { Experimental } \\
\text { (ppm) }\end{array}$ \\
\hline C-1 & 30.07 & 29.86 & $C-1$ & 18.63 & \\
\hline C-2 & 142.42 & & $C-2$ & 143.93 & \\
\hline C-3 & 130.47 & & $C-3$ & 132.05 & 132.8 \\
\hline C-4 & 33.30 & & C- 4 & 30.30 & \\
\hline C-5 & 37.22 & & $C-5$ & 36.75 & \\
\hline C- 6 & 149.49 & & $C-6$ & 149.79 & \\
\hline C-7 & 129.63 & & $C-7$ & 135.80 & \\
\hline C-8 & 128.41 & & C-8 & 136.78 & \\
\hline C-9 & 135.29 & & C-9 & 139.36 & \\
\hline C- 10 & 142.69 & & $C-10$ & 147.11 & \\
\hline C-11 & 133.92 & & $C-11$ & 136.14 & 136.32 \\
\hline C-12 & 125.19 & 125.89 & C- 12 & 137.90 & 137.51 \\
\hline C-13 & 140.11 & & $C-13$ & 141.50 & \\
\hline C- 14 & 137.59 & 137.51 & C- 14 & 147.26 & \\
\hline C-15 & 135.04 & & C- 15 & 137.91 & \\
\hline C-16 & 129.67 & & $C-16$ & 140.40 & \\
\hline C-17 & 16.96 & & $C-17$ & 20.31 & \\
\hline C-18 & 27.34 & 26.85 & C- 18 & 17.75 & 17.85 \\
\hline C-19 & 17.49 & 17.11 & C- 19 & 14.99 & \\
\hline C-20 & 14.92 & 14.27 & $C-20$ & 14.83 & \\
\hline$C-1^{\prime}$ & 24.33 & & $C-1^{\prime}$ & 25.00 & 25.85 \\
\hline$C-2^{\prime}$ & 144.17 & & $C-2^{\prime}$ & 142.47 & \\
\hline $\mathrm{C}-3^{\prime}$ & 129.71 & & $C-3^{\prime}$ & 133.26 & \\
\hline$C-4^{\prime}$ & 32.43 & 32.08 & $C-4^{\prime}$ & 35.60 & \\
\hline$C-5^{\prime}$ & 38.78 & 40.39 & $C-5^{\prime}$ & 35.78 & \\
\hline$C-6^{\prime}$ & 151.21 & & $C-6^{\prime}$ & 143.64 & \\
\hline C- $7^{\prime}$ & 131.66 & 131.89 & $C-7^{\prime}$ & 135.53 & 135.56 \\
\hline$C-8^{\prime}$ & 128.79 & & C- $8^{\prime}$ & 135.27 & \\
\hline C- $9^{\prime}$ & 134.52 & & C- $-9^{\prime}$ & 139.31 & 139.64 \\
\hline$C-10^{\prime}$ & 145.60 & & $C-10^{\prime}$ & 144.23 & \\
\hline $\mathrm{C}-11^{\prime}$ & 130.72 & & $\mathrm{C}-11^{\prime}$ & 134.98 & \\
\hline C- $12^{\prime}$ & 126.03 & & C- $12^{\prime}$ & 136.11 & \\
\hline C- $13^{\prime}$ & 138.24 & & C-13' & 141.44 & \\
\hline C- $14^{\prime}$ & 139.06 & 139.64 & C-14' & 144.93 & \\
\hline C- $15^{\prime}$ & 135.57 & 135.56 & C-15' & 136.76 & 136.70 \\
\hline C- $16^{\prime}$ & 130.22 & 130.23 & C- $16^{\prime}$ & 138.18 & \\
\hline C- $17^{\prime}$ & 25.62 & 25.85 & C- $17^{\prime}$ & 19.44 & \\
\hline C- $18^{\prime}$ & 17.55 & 17.85 & C- $18^{\prime}$ & 14.37 & 14.27 \\
\hline C- $19^{\prime}$ & 19.16 & & C-19' & 13.10 & 13.06 \\
\hline C- $20^{\prime}$ & 15.32 & & C- $20^{\prime}$ & 13.42 & \\
\hline
\end{tabular}

Labeling according to Figure S3A (Supplementary Information). 

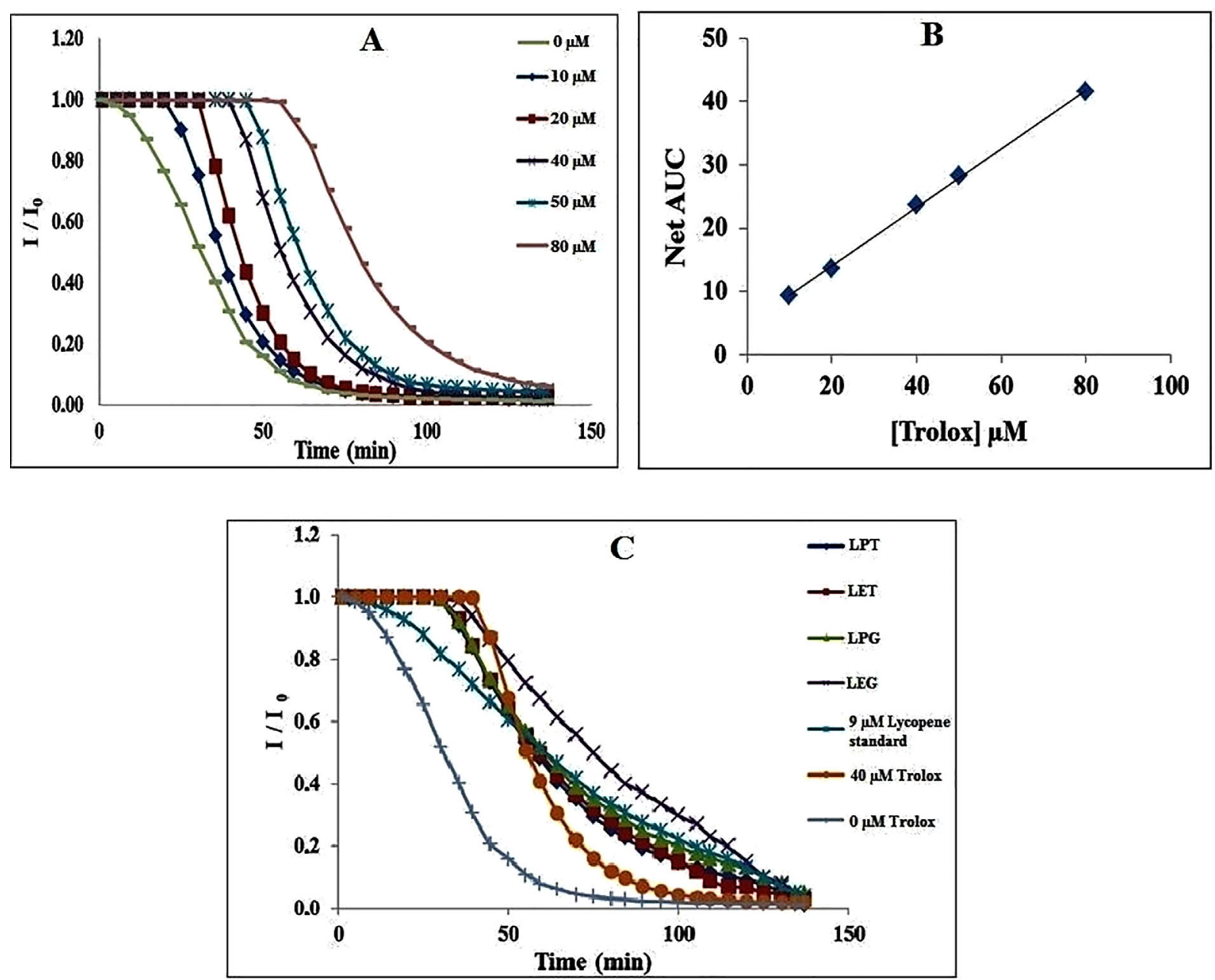

Figure 5. ORAC: Trolox standards (A), Trolox $40 \mu \mathrm{M}$, Lycopene standard $9 \mu \mathrm{M}$, LEG, LET, LPG, LPT (C), and Standard curve (B).

once it has been found that the mixture of these carotenoids resulted in more effective inhibition of free radicals in extracts sample. This fact justifies that the major antioxidant activity of LEG is correlated with the carotenoid synergism in guava extract.

\subsection{In Vitro Antibacterial Activity}

Lycopene, which is a well-known red carotenoid pigment, has been drawing scientific interest because of its potential biological functions. So, the antioxidant activity of lycopene from different vegetables has been reported previously. ${ }^{[1,39]}$

However, few works have investigated lycopene antimicrobial activity. A study by Difaby et al. ${ }^{[9]}$ showed the antibacterial effect of an extract rich in Lycopene and $\beta$-carotene against two species of Gram-positive bacteria and three species of Gram-negative bacteria. According to these authors, carotenoid extracts could be good sources of bioactive compounds with antimicrobial potency.

Thus, it is clear that carotenoid extracts were effective in controlling both Gram types of bacteria. This evidence suggests the presence of several potential bioactive compounds within the carotenoid extract, which may act by synergism or additive effect. $^{[40]}$

In general, comparing the MIC values obtained for all microorganisms tested in this study to those reported by Djifaby et al. ${ }^{[9]}$ for extracts rich in carotenoids from Guiera senegalensis, it is possible to observe that the values obtained in this work were significantly lower $\left(0.95-1.92 \mathrm{mg} \mathrm{mL}^{-1}\right.$ of lycopene versus $1.5-6.25 \mathrm{mg} \mathrm{mL}^{-1}$ ). This fact can be due to the different content of carotenoids existent in G. senegalensis and eventually the different extraction techniques used, what can influence in the extraction of a specific group of bioactive compounds and affecting antimicrobial properties. Paz et al. ${ }^{[10]}$ reported MIC values for Brazilian fruit extracts tested in different microorganisms in the range $10-400 \mathrm{mg} \mathrm{mL}^{-1}$ and Piccirillo et al. ${ }^{[41]}$ also found MIC values for extracts from ginja cherry plant, considerably higher $\left(10-100 \mathrm{mg} \mathrm{mL}^{-1}\right)$ than those registered in this work.

The results found in this study for MBC are in accordance with those previously reported by Silva et al. ${ }^{[25]}$ for blueberry extracts that did not find MBC values, once it is definitely hard to destroy spores. In contrast, Djifaby et al. ${ }^{[9]}$ reported for $B$. cereus an $\mathrm{MBC}$ range of $1.5-12.5 \mathrm{mg} \mathrm{mL}^{-1}$ for different branch extracts of $G$. senegalensis. 
Therefore, antimicrobial activity showed that it is possible to use carotenoid extracts from guava as natural antimicrobials with wide potential applications in the pharmacy, cosmetics, and food industries.

\section{Conclusion}

This work demonstrated that the extracts from guava contained higher amounts of lycopene than tomato, and the detailed carotenoid composition of guava and tomato was successfully determined by HPLC-DAD and MS/MS for the first time. The theoretical NMR results showed that lycopene extracted from guava might have $5-Z$ configuration.

Good simple correlations were found to TEAC and ORAC, with more statistically significant correlations found for LEG in guava. Both samples, LEG and LET, exhibited antibacterial activity against three bacteria (E. coli, L. innocua, and S. aureus) and lower antimicrobial activity against $B$. cereus. To the best of our knowledge, this is the first study reporting the bioactivity of lycopene extracts from Brazilian guava.

These biological properties permit to state guava extracts application as multifunctional food additive, namely attributed to natural color combined with antimicrobial and antioxidant activity. The amount of lycopene present in guava makes this fruit an economical potential for guava by-products.

\section{Abbreviations}

Coastal Tablelands District of Piauí: DITALPI - EBV 4; Delta of Parnaíba Herbarium: HDELTA-UFPI; Ultraviolet-Visible: UV-Vis; High Performance Liquid Chromatographic - Diode Array: HPLC-DAD; Electrospray Mass Spectroscopy: ESI - MS; X-Ray diffractogram: XRD; Infrared Spectrometry: FTIR; Lycopene Extract from $P$. guajava: LEG; Lycopene Extract from Tomato: LET; Isolated lycopene from P. guajava: LPG; Isolated lycopene from Tomato: LPT; Retention time: RT; Nuclear Magnetic Resonance: NMR; Minimum inhibitory concentrations: MIC; Minimum bactericidal concentration: MBC.

\section{Acknowledgements}

A. A. is grateful to CAPES by PDSE process no $99999.004236 / 2014-09$ in the CBQF of the Portuguese Catholic University (UCP), supported by National Funds from FCT - Fundação para a Ciência e a Tecnologia through the project PEst-OE/EQB/LA0016/2013. BIOTEC is grateful to Phytobios LTDA and to Delta of Parnaíba Herbarium (HDELTA) - UFPI. B. G. and A. O. are grateful to Foundation to Science and Technology (FCT) fellowship reference SFRH/BPD/79941/2011 and PhD grant SFRH/BD/75041/2010, respectively. A. M. is grateful to FAPESP (grant 2014/02282-6). Y. M. was supported by CNPq (Grant 165177/2014-4).

\section{References}

[1] K. W. Kong, N. F. Rajab, K. N. Prasad, A. Ismail, M. Markom, C.-P. Tan, Food Chem. 2010, 123, 1142.

[2] H. Phan-Thi, Y. Waché, Food Chem. 2014, 156, 58.

[3] C. M. Stinco, F. J. Rodríguez-Pulido, M. L. Escudero-Gilete, B. Gordillo, I. M. Vicario, A. J. Meléndez-Martínez, Food Res. Int. 2013, 50, 111.

[4] M. Honda, N. Takahashi, T. Kuwa, M. Takehara, Y. Inoue, Y. Kumagai, Food Chem. 2015, 171, 323.

[5] M. Seifi, P. Seifi, F. Hadizadeh, S. A. Mohajeri, J. Food Sci. 2013, 78, C1680.

[6] M. A. El-Raey, G. E. Ibrahim, O. A. Eldahshan, J. Pharm. Phyt. 2013, 2, 245.

[7] I. J. P. Colle, L. Lemmens, S. V. Buggenhout, K. Met, A. M. V. Loey, M. E. Hendrickx, Food Res. Int. 2013, 51, 32.

[8] R. J. Fair, Y. Tor, Perspect. Med. Chem. 2014, 6, 25.

[9] S. P. A. E. Djifaby, C. A. Yacouba, H. Adama, K. Kiessoum, C. M. Marie-Hyacinthe, N. O. Germaine, Int. J. Phyt. 2012, 4, 441.

[10] M. Paz, P. Gúllon, M. F. Barroso, A. P. Carvalho, V. F. Domingues, A. M. Gomes, H. Becker, E. Longhinotti, C. Delerue-Matos, Food Chem. 2015, 172, 462.

[11] The Angiosperm Phylogeny Group, Bot. J. Linn. Soc. 2009, 161, 105.

[12] International Plant Names Index. 2012. http://www.ipni.org/ipni/ plantnamesearchpage.do

[13] A. G. N. Amorim, J. R. S. A. Leite, C. D. Ropke, Inventors, Phytobios, co-assigne, UFPI, assigne, Obtenção de extrato rico em licopeno e licopeno puro de fonte natural. 2016, BR 102016 030594-2.

[14] L. R. B. Mariutti, E. Rodrigues, A. Z. Mercadante, J. Food Compos. Anal. 2013, 31, 155.

[15] S. Pennathur, D. Maitra, J. Byun, I. Sliskovic, I. Abdulhamid, G. M. Saed, M. P. Diamond, H. M. Abu-Soud, Free Radic. Biol. Med. 2010, 49, 205.

[16] M. Takehara, M. Nishimura, T. Kuwa, Y. Inoue, C. Kitamura, T. Kumagai, M. Honda, J. Agr. Food Chem. 2014, 62, 264.

[17] P. Hohenberg, W. Kohn, Phys. Rev. 1964, 136, B864.

[18] M. J. Frisch, G. W. Trucks, H. B. Schlegel, G. E. Scuseria, M. A. Robb, J. R. Cheeseman, G. Scalmani, V. Barone, B. Mennucci, G. A. Petersson, Gaussian 09, Revision A.02, Gaussian Inc Wallingford CT 34, Wallingford CT 2009, http://www.gaussian.com/index.htm

[19] San Diego: Accelrys Software Inc. Discovery Studio Modeling Environment, 650 Release 3.5.| Accelrys Software Inc. 2012.

[20] C. Lee, W. Yang, R. G. Parr, Phys. Rev. B. 1988, 37, 785. http://prb. aps.org/abstract/PRB/v37/i2/p785_1

[21] K. Wolinski, J. F. Hinton, P. Pulay, J. Am. Chem. Soc. 1990, 112, 8251.

[22] M. S. Gião, M. L. González-Sanjosé, M. D. Rivero-Pérez, C. I. Pereira, M. E. Pintado, F. X. Malcata, J. Sci. Food Agr. 2007, 87, 2638.

[23] P. J. Brescia, BioTek 2012, 1, 1-4.

[24] B. P. Arathi, P. Raghavendra, R. Sowmya, K. Vijay, P. Dilshad, B. Saikat, V. Gopal, R. Lakshminarayana, Food Anal. Methods 2015, 8, 1962.

[25] N. A. Silva, E. Rodrigues, A. Z. Mercadante, V. V. Rosso, J. Agr. Food Chem. 2014, 62, 5072.

[26] G. A. Chasse, M. L. Mak, E. Deretey, I. Frakas, L. L. Torday, J. G. Papp, D. S. R. Sarma, A. Agarwal, S. Chakravarthi, S. Agarwal, A. V. Rao, J. Mol. Struc. Theochem. 2001, 571, 27.

[27] J. Irudayaraj, J. Tewari, Appl. Spectrosc. 2003, 57, 1599.

[28] W. Qiu, H. Jiang, H. Wang, Y. Gao, Food Chem. 2006, 97, 516. 
[29] I. R. Bunghez, M. Raduly, S. Doncea, I. Aksahin, R. M. Ion, Dig. J. Nanomater Bios. 2011, 6, 1349.

[30] M. Honda, T. Kudo, T. Kuwa, T. Higashiura, T. Fukaya, Y. Inoue, C. Kitamura, M. Takehara, Biosci. Biotechnol. Biochem. 2017, 81, 2.

[31] A. Lebail, H. Duroy, J. L. Fourquet, Mater. Res. Bull. 1988, 23, 447.

[32] K. Murakami, M. Honda, R. Takemura, T. Fukaya, M. Kubota, H. Wahyudiono Kanda, M. Goto, Biochem. Biophys. Res. Commun. 2017, 491, 317.

[33] A. Vallverdú-Queralt, S. Arranz, I. Casals-Ribes, R. M. LamuelaRaventós, J. Agr. Food Chem. 2012, 60, 1981.

[34] M. Richelle, P. Lambelet, A. Rytz, I. Tavazzi, A.-F. Mermoud, C. Juhel, P. Borel, K. Bortlik, Br. J. Nutr. 2013, 107, 1482.

[35] C. M. Stinco, F. J. Heredia, I. M. Vicario, A. J. Meléndez-Martínez, LWT - Food Sci. Tech. 2016, 65, 718.

[36] L. Müller, P. Goupy, K. Fröhlich, O. Dangles, C. Caris-Veyrat, V. Böhm, J. Agr. Food Chem. 2011, 59, 4504.

[37] J. E. Dávila-Aviña, J. A. Villa-Rodríguez, M. A. Villegas-Ochoa, O. Tortoledo-Ortiz, G. I. Olivas, J. F. Ayala-Zavala, G. A. GonzálezAguilar, J. Food Sci. Tech. 2014, 51, 2706.

[38] F. J. Eller, J. K. Moser, J. A. Kenar, S. L. Taylor, J. Am. Oil. Chem. Soc. 2010, 87, 755.

[39] M. C. Gámez, M. M. Calvo, M. D. Selgas, M. L. García, K. Erler, V. Böhm, A. Catalano, R. Simone, P. Palozza, J. Agr. Food Chem. 2014, 62, 1557.

[40] S. Voravuthikunchai, A. Lortheeranuwat, W. Jeeju, T. Sririrak, S. Phongpaichit, T. Supawita, J. Ethnopharmacol. 2004, 94, 49.

[41] C. Piccirillo, S. Demiray, A. C. S. Ferreira, M. E. Pintado, P. M. L. Castro, Ind. Crops Products 2013, 43, 562. 